Open Access

\title{
Innovative behavior and the Chinese enterprise survival risk: an empirical research
}

Zongke Bao

Correspondence: 154486901@163.com

School of Accounting, Zhejiang University of Finance and Economics, 310018 Hangzhou, China

\begin{abstract}
The Chinese firms face enormous survival risk in economic transition, with an average life expectancy of less than 4 years. We employ propensity score matching and Cox model to overcome the sample bias and right censoring, investigate the inhibitory effect of innovation to firm survival risk both static and dynamic dimensions. There are the following findings from this paper. First, compared with the non-innovative enterprises, the innovative enterprises own higher competence of risk resistance, as innovative activities can release about 12\% survival risk for enterprises and extend their survival time by 0.84 year. Second, the influence of innovative intensity on the enterprises' survival probability presents the characteristics of being non-stationary rather than proportional, which means the stronger innovative intensity will not necessarily bring more obvious inhibition effect. Third, the characteristics of being different within enterprises will change the effect of innovation activity on inhibiting survival risk. The survival incremental effect of large-scale enterprises with high productivity through innovative activities is more apparent, as innovative activities help to relieve the agglomeration of survival risk from those long-established enterprises. But those enterprises with financing limit are not suitable for innovative activities.
\end{abstract}

Keywords: Innovative behavior, Survival risk, Cox risk model, Treatment effect JEL: D21, L25, L60

\section{Background}

As China's market-oriented reform steps gradually into the "abyssal region," its macroenvironment has also become increasingly dynamic and complex, putting forward higher demands for the business to conduct continuous operation. In this stage, a large number of enterprises with low efficiency choose to or are forced to leave the market, even including many reputable household names of century-old shops such as Wang Mazi and Zhang Xiaoquan, both of which have undergone profit decline, suspension, or even bankruptcy. A large number of literatures have shown that high dropout rates from the market are a striking feature of China's transitional process, which can be testified by most of the industry with the characteristics of high dropout rates (Caves 1998). According to the statistics made by Qilin and Bin (2013) on the Chinese manufacturing enterprises exiting from the market from 1999 to 2006, there had been an

(c) The Author(s). 2016 Open Access This article is distributed under the terms of the Creative Commons Attribution 4.0 International License (http://creativecommons.org/licenses/by/4.0/), which permits unrestricted use, distribution, and reproduction in any medium, provided you give appropriate credit to the original author(s) and the source, provide a link to the Creative Commons license, and indicate if changes were made. 
average about $17 \%$ of the incumbent firms exiting the market each year. Setting aside whether this high flow characteristics can improve China's macroeconomy efficiency, a more direct and realistic problem is that facing enormous survival risk, Chinese enterprises usually can only successfully operate business in a quite short period. According to the statistics from the White Paper of Human Resources Management on China's Small and Medium-sized Enterprises, the average survival time of Chinese companies is about 3.6 years, among which the average survival time of the small- and mediumsized enterprises is much shorter, at around only 2.5 years, far less than those Euro-American counterparts with an average life expectancy of more than 40 years. It is safe to say that most Chinese enterprises have been repeating the path on which they make a fortune for the first year, getting richer in the second, but fail in the third. Only a scantly few companies sustain and expand their scale. So, how to reduce the enterprises' survival risk and increase the enterprises' survival time is an extremely important research topic for Chinese scholars.

In recent years, there are already literatures focusing on the decisive factors related to the Chinese enterprises' survival risk. Such theories as system evolution, market selection, international trade have been proposed (Jiao et al. 2015; Xingzhi et al. 2014; Yuduo et al. 2014). However, there is a fact which is easily ignored by policy makers and theory circle-the ratio between research and development spending and sales revenue of all the enterprises exiting the market in 2006 was around $0.036 \%$, far less than that of incumbents at $0.045 \%$. This incurs a question naturally: does zero innovation increase the risk of enterprises' survival and shorten their survival time in the market? Recently, it has been clearly put forward in the report at the 18th Party Congress that China will implement the national strategy of innovation-driven development which stipulates that the innovation drive is the requirement of the transformation of economic development pattern at the macro level and the source of innovation drive is to improve enterprise efficiency at the micro level. Therefore, the answers to these questions will help inspect the microscopic approach by which the efficiency of the enterprise survival is improved by innovation-driven strategy.

In the early 1930s, Schumpeter put forward the viewpoint of "creative destruction" on industrial evolution. "Creative destruction" is the typical characteristics of market economy whose structure is created and destroyed by the competition on innovation between different main bodies. Each destruction can eliminate some backward production technology and production methods, leading enterprises to merger or perish (Hopenhayn 1992). The evolution model made by Pakes and Ericson (1998) provided an important theoretical perspective for the relationship between innovation and survival. Assume there is self-selection effect of production efficiency distribution in the market, enterprises can change the productivity efficiency distribution by researching and developing investment activities as well as technology. If the enterprises' productivity is lower than the lowest productivity required to remain in the market, the enterprise will exit the market through the selection effect. Such exit can be understood as a process in which the enterprises with higher productivity caused by innovation squeeze those with lower productivity out of the market as a result of innovation. It is undeniable that innovative activities will not necessarily enhance the distribution of the enterprises' productivity distribution, as innovation implies a high degree of uncertainty which may worsen the productivity distribution of the enterprise. 
In empirical studies, the relationship between innovative behavior and enterprise survival has always been a hot issue in the field of micro research. But so far, there are many contradictions in existing literature, so there are no uniform conclusions. There is one viewpoint that regards innovation as the essence of the enterprise survival from the perspective of industrial organization. Only innovative companies can establish and maintain a competitive advantage in the market, making enterprises' profitability significantly higher than that of the non-innovative enterprises. Thus, the enterprises' duration in the market will expend (Audretsch and Mahmood 1995; Geroski 1995; Fontana and Nesta 2009). Esteve and Ssanchis-Llopis (2010) has measured and calculated the exit risk for enterprises conducting financial innovative activities, concluding that their risk rate is $57 \%$ lower than those who do not. This gap is more prominent in export enterprise. Cefis and Marsili (2005) have further measured the survival premium of successful innovation on the basis of transition probability matrix and found that successful innovation can increase enterprises' survival time by about $11 \%$.

The alternative view is developed in recent years, according to which the relationship between innovation and enterprise survival is complex and regulated by many factors. For instance, the difference in characteristics inside the enterprises and the difference in the industry cause a great amount of uncertainty between innovation and survival time. Esteve and Mañez-Castillejo (2008) found that only in the highly innovative industry can innovative behavior extends the survival time in the market. Bayus and Agarwal (2007) also think that the industrial difference is one of the important conditions to establish such relationship which is relatively longer in technology-intensive industries. There are also some other similar literature written by Zhen and Xue (2014) and Jianbai et al. (2010). In the study into the adjustment of the difference on enterprises' internal characteristic, Ortega-Argiles and Moreno (2005) argue that only in small enterprises can this positive correlation be set up. Cefis and Marsili (2005) found the highest survival premium resulted from innovation exist in newly established and small-scale enterprises by non-parametric method and a $23 \%$ increase of survival probability was found in young small businesses. Esteve and Ssanchis-Llopis (2010) considered the characteristics of enterprises to export. Buddelmeyer et al. (2010) focused on the enterprises' capital scale, while Xingzhi et al. (2014) analyzed the expansion of enterprise behavior.

In general, there are already a few studies into the survival effect of innovative behavior in existing literature, although there are no uniform conclusions yet. By contrast, systematic study of Chinese enterprises' survival from the angle of innovation is very scarce. In fact, for China's economy in the rapid transformation, the innovation incentive of the enterprise survival is particularly worthy of our attention and research. In present stage, Chinese companies especially for small- and medium-sized enterprises whose innovation impetus are grossly inadequate are generally reluctant to invest in innovation. On the one hand, market uncertainty and high transaction cost lead to great cost for innovational failure which is likely to cause the enterprise bankrupt or even to be expelled from the market. On the other hand, the imperfections in such laws as protection of intellectual property rights and property rights system lead to a rather low enterprise innovation premium rate. The former causes enterprise too timid to undertake innovation, while the latter can lead enterprises "unwilling" to innovate. This paper aims to reveal that innovative behavior can bring enterprise with survival 
premium and can effectively reduce the enterprises' survival risk in order to extend their survival time. Therefore, the empirical research in this paper can be the basis for Chinese enterprises to make investment into innovation, especially for small- and medium-sized enterprises, which will further support innovation-driven national strategy.

Compared with the existing literature, the contribution of this paper mainly has two aspects: first, the methodological innovation, that is, the solution for problems such as sample selection bias and censoring of data with long duration through the method of matching scores for tendency and Cox survival model. On the one hand, it is undeniable that there exists obvious selection bias problem in this article's sample data. Enterprises' innovative behavior is not randomly distributed, but is the result of their own choice. Enterprises' survival time has a positive impact on the development of new products and innovation output (Sivadas and Dwyer 2000; Tripsas and Gavetti 2000. In order to solve this problem, this paper tends to use the method of propensity score matching to construct a controlling group which has similar main characteristics of the enterprise before conducting innovative activities and then to capture the average differences in survival time of the experimental group and control group to avoid selectivity bias problem of samples. On the other hand, there are usually data censoring problem for data with long duration. This means that when the study began, some companies were already existing in the market, or when the study ended, some companies had not been withdrawn from the market. We then adopted the following measures: firstly, eliminate the samples already existed before 2000 and track the dynamic like the life cycle of those enterprises entering the market after the year 2000 in order to overcome left merge problem; second, whether using a virtual variable to record observations of individual enterprise cycle is complete and whether Cox survival model can solve the problem in the duration data's right merge. Then, we capture the appropriate optimal innovation strength of the enterprise survival, which enrich the literature of enterprise innovation and survival.

\section{The innovative behavior and the statistical fact of Chinese enterprises' survival time \\ Sample data}

The data in this paper are from "China's Industrial Enterprise Database" spanning from 2000 to 2007. This database includes all the basic information and financial data of the state-owned and non-state-owned enterprises above designated size. In order to improve the accuracy of the estimated results, we did a preliminary screening by referring to literature written by Jiao et al. (2015). Obviously, the survival time of the enterprise in the market should be classified as data with a long duration. For this kind of data, there are usually problems with data merging problems (censoring), which means when the study began, some companies already exist in the market, or when the end of the study, some companies have not been withdrawn from the market. In general, this merge problem produces the estimation errors. To improve the accuracy of survival estimate, we take the year 2000 as the base, delete enterprises existing before 2000, so we can overcome the problems of left merge for data with a long duration.

We identify the enterprises' survival time in market mainly through the enterprise code in database. Similar to Jiao et al. (2015) and Namini et al. (2013), we define 
enterprises' survival time in the market as the period in which the enterprise entered the market for the first time until it exited. If the enterprise code does not exist in $t$ term, but appears in $t+1$ term, then we can basically make the judgment that the enterprise enters the market in " $t+1$ " term, so is the definition of its exit. In addition, in order to further improve the accuracy of identifying individual enterprises, we also match information such as name, telephone number, and postal code and ensure observation samples of the same enterprise attached with the same code. There is one point that is worth special attention, that is, the subjects covered by the database are all state-owned enterprises and non-state-owned enterprises above designated size. Then, in enterprise code, there may be cases of erroneous judgment on enterprises in which the enterprises are mistaken as entry firms but are actually sustaining with changes on scale or the enterprise disappears but appear again years later. We found that of all the companies entering the market after 2000, there are fault samples in a total of 1436 enterprises. To simplify the process, we will eliminate these samples.

As there is no accurate method to measure the intangible assets from the perspective of accounting standards, and the measurement on innovation by existing research is almost dependent on proxy variables, the most common measures are R\&D (Esteve and Mañez-Castillejo 2008) and the number of applied patent. These two indicators represent the different stages of enterprise innovation. Patent number measures the output of innovative activities, but this only represents a small portion of the original innovation activity (Kleinknecht et al. 2002), and the distribution of patent information is highly left-skewed (Harhoff et al. 1999). R\&D can accurately reflect the current innovative behavior, and also can measure the enterprises' innovative process, so $R \& D$ spending is a reasonable variable of enterprises' innovative activities. The practice of Lin (2013) can be referred, that is, to use the new product production in database as the proxy variable of R\&D. Finally, the number of sample enterprises after screening is 39,762, among which 28,351 companies belong to the category of non-innovative enterprises and 11,411 innovative enterprises accounting for $28.70 \%$ of total samples.

\section{The preliminary statistical analysis of Chinese enterprise survival time}

Because of the complexity of the data structure, non-parametric estimation methods such as risk function or survival function are generally used in the analysis of data with a long duration to track the distribution features of the individual enterprises' survival time (Yong-bing et al. 2013). These methods do not require to make prior assumptions on the probability distribution of the data, also do not need to estimate parameters, so it is more suitable for exploratory analysis. Survival function $S(t)$ refers to the probability of individual enterprises' survival time exceeding time $t$. If there is no problem of right merge in the data structure, we can simply define the survival function as the proportion of the enterprises whose survival time exceeds time $t$ among all enterprises. Otherwise, Kaplan-Meier estimator is needed for analysis, for in the case of independent merge, it is still a consistent estimator of $S(t)$.

Based on survival analysis method, we estimated the survival status of those enterprises entering the market after 2000. Two typical facts can be found in Table 1: first, generally speaking, the duration of the Chinese enterprises' market management is very 
Table 1 The distribution of survival time of Chinese enterprises (entering the market after the year 2000)

\begin{tabular}{|c|c|c|c|c|c|c|}
\hline & \multirow{2}{*}{$\begin{array}{l}\text { Average survival } \\
\text { time }\end{array}$} & \multirow{2}{*}{$\begin{array}{l}\text { Number of } \\
\text { enterprises }\end{array}$} & \multicolumn{4}{|c|}{ The proportion of survival time } \\
\hline & & & $\begin{array}{l}1 \text { year } \\
(\%)\end{array}$ & $\begin{array}{l}\text { 2 4 years } \\
(\%)\end{array}$ & $\begin{array}{l}5 \sim 7 \text { years } \\
(\%)\end{array}$ & $\begin{array}{l}8 \text { years and } \\
\text { above (\%) }\end{array}$ \\
\hline Innovative enterprises & 6.32 & 11,411 & 15.57 & 29.68 & 38.34 & 16.41 \\
\hline Non-innovative enterprises & 4.31 & 28,351 & 25.83 & 35.82 & 29.16 & 9.19 \\
\hline All enterprises & 4.89 & 39,762 & 23.53 & 33.04 & 32.54 & 10.89 \\
\hline
\end{tabular}

short, with an average of survival time of just 4.89 years. The number of enterprises whose survival time is above 8 years accounted for only $10.89 \%$, which is far lower than the average level of developed countries, showing that in the process of market transition, dynamic market environment put forward a bigger challenge for the enterprise to continue its operation, which is inevitably accompanied by characteristics of high market flow including entry and exit. The enterprise that has just entered the market faces huge risk of being expelled from the market, which can be illustrated by $23.53 \%$ of enterprises dying in the first year and $56.57 \%$ of enterprises whose survival time is less than 4 years. The distribution of survival time presents typical features of right avertence, which implies that only a small number of firms survive longer than average survival time. This means that with the background of economic transition, there is a lower chance for enterprises just entering the market to survive. But after the initial phase, their life expectancy begins to increase (Audretsch 1995 and Audretsch and Mahmood 1995).

In the second place, from the perspective of classification of innovative enterprises and non-innovative enterprise group, we can find that the performance of innovative enterprises or those with a survival time of more than 8 years is much more steady than non-innovative enterprises in both the average survival time and the exit status in the first year of coming into the market. The average survival time of innovative enterprise is 6.32 years, nearly $50 \%$ higher than the non-innovative enterprise whose average survival time is 4.31 years. The proportion of exit among innovative enterprises is only $15.57 \%$, about $10 \%$ lower than non-innovative enterprises whose ratio of survival within 1 year is $25.83 \%$, while innovative enterprise with 8 years of continuous operation account for $16.41 \%$, far higher than the ratio of innovative enterprise at $9.19 \%$.

Based on Kaplan-Meier survival function, in Fig. 1, it is depicted that the innovative enterprises and the enterprises' survival time of survival function estimation, we can clearly find that on the one hand, with the passage of time, both the innovation and the innovation of enterprises' survival probability is gradually reduced, especially for the non-innovative enterprises; their survival probability is significantly reduced. On the other hand, the difference between the survival probability of innovative enterprises and non-innovative enterprises appeared to be enlarged year by year. This suggests that with the passage of the time, innovative enterprises' survival probability will be significantly greater than the innovative enterprises. Further, Fig. 1 also describes risk function of both the innovative and non-innovative enterprises. It can be found that although the tendency of the risk function of two kinds of enterprises is roughly the same, there exists higher risk of failure in the non-innovative enterprises than the 


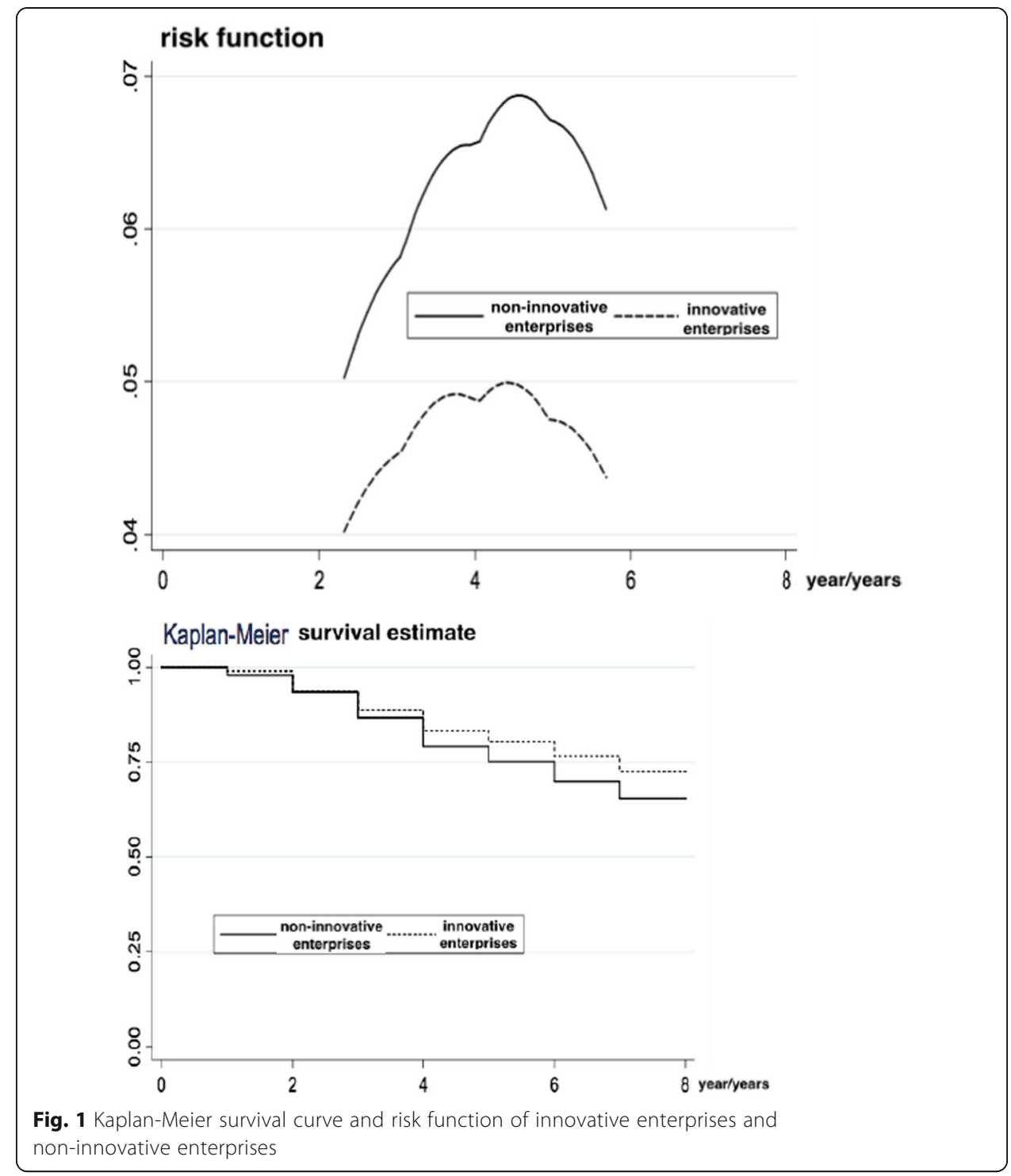

innovative enterprise, with the difference on risk of failure at about $30 \%$, which means that the innovative enterprises have better ability to resist risk.

\section{Methods}

This study aims to reveal the influence of enterprises' innovative behavior on enterprises' survival risk, namely whether there is a causal relationship between innovative behavior and enterprises' survival risk. Before designing study methods, we need to sort out the fact that there may be a logical relationship between the two: enterprises' innovative activities may be affected by the enterprises' survival time. Although there is no consensus in the theoretical circle on the impact of enterprises' age on innovative activities, it is undeniable that enterprises' age is an important factor influencing innovative activities (Yan-ying and Zongke 2015; Coad et al. 2010). For Chinese companies, in particular, imitation innovation is the important driving force of China's economic growth in the past 30 years. The absorption of the imitation innovation can be gained through the long time survival in the market of the enterprise. That is to say, 
the enterprise innovative behavior is not randomly distributed, but also is the result of the enterprises' own choice. Innovative behavior is not only a factor affecting the enterprises' survival time but also likely to be a result of the enterprises' continuous survival. It is safe to say that there is severe selection bias in research samples in this paper. So, we need a careful study design to overcome the problem of selection bias resulting from reverse causation.

By using the propensity score matching method, we artificially constructed a group of enterprises with similar main characteristics with those innovative enterprises prior to innovation to simulate the treatment effect. Propensity score matching method is a widely recognized appropriate method to deal with the binary variable in theory circle. The main idea of propensity score matching is as follows: first, set the innovative enterprise as the experimental group and then build a control group with similar characteristics to innovative enterprises before the innovation; second, eliminate the differences on characteristics of those individual enterprises in different groups by matching the subject of control group with experimental group to ensure that there is only difference on innovative behaviors between them, which will simulate the survival characteristics of those non-innovative enterprises in the condition of "zero innovation". Third, compare the average difference on survival time between the control group and experimental group to capture the causal relationship between the enterprise innovative behavior and survival time.

\section{Propensity score matching}

Identify experimental group and control group

According to whether there is innovational behavior, we classify samples into experimental group and control group. Experimental group is designed to be a group in which a new product value is above zero, while control group includes non-innovative enterprises whose new product value is zero. We establish a binary virtual variable Creation $_{i t}=\{0,1\}$, designate innovative enterprisess' value is 1 and the value of noninnovative enterprise is 0 . Set enterprises' survival time as Time, then the average effect of the innovation on the enterprises' survival time is

$$
E\left\{\text { Time }_{i t}^{1}-\text { Time }_{i t}^{0} \mid \text { Creation }_{i t}=1\right\}=E\left\{\text { Time }_{i t}^{1} \mid \text { Creation }_{i t}=1\right\}-E\left\{\text { Time }_{i t}^{0} \mid \text { Creation }_{i t}=1\right\}
$$

In this formula, Time ${ }_{i t}^{1}$ refers to innovative enterprises' survival time and Time ${ }_{i t}^{0}$ refers to non-innovative enterprises' survival time. In the above formula, $E$ $\left\{\right.$ Time $_{i t}^{0} \mid$ Creation $\left._{i t}=1\right\}$ refers to the survival time of innovative enterprise before innovative behaviors, which is a counter fact.

\section{Data matching}

The process of matching data is the key step in propensity score matching, aiming to ensure the matching variables of successfully matched control group and experimental group as alike as possible. The matching variables need to be designated in propensity score matching, a factor that influences enterprises' innovative behavior and enterprises' survival simultaneously. According to the existing theoretical and empirical literature, the matching variables we select are as shown in Table 2. 
Table 2 The measurement method of matching variable

\begin{tabular}{|c|c|c|}
\hline Symbol & Name of variables & Measurement methods \\
\hline Size & Scale of enterprises & $\begin{array}{l}\text { Logarithm of enterprise sales, sales deflate in accordance with } \\
\text { the producer price index in } 2000\end{array}$ \\
\hline TFP & Enterprises' production & Using the OP measure method (1996) to calculate \\
\hline Finance & Financing constraints & The ratio of interest payments and fixed assets \\
\hline Capital & Capital intensity & $\begin{array}{l}\text { The ratio of fixed assets and employees, fixed assets deflates } \\
\text { according to the price index of investment in fixed assets of } 2000\end{array}$ \\
\hline Profit & Return on sales & The ratio of operating profit and sales revenue \\
\hline Resource & Human capital & $\begin{array}{l}\text { The ratio of workers with college bachelor degree or above } \\
\text { among all staff }\end{array}$ \\
\hline Export & Export intensity & The ratio of export delivery value and enterprise sales \\
\hline Debt & Asset liability ratio & The ratio of enterprises' liabilities and assets \\
\hline
\end{tabular}

Next, we take the Logit method for the regression of binary variables and regard estimated coefficient of each covariant as weights, fitting out the propensity score of each enterprise. The specific calculation process is

$$
\operatorname{PS}\left(X_{i t}\right)=\operatorname{Pro}\left(\text { Creation }=1 \mid X_{i t}\right)=\frac{\exp \left(\alpha X_{i t}\right)}{1+\exp \left(\alpha X_{i t}\right)}
$$

In this formula, $X$ refers to the matching variable. The score reflects the probability of a certain enterprises' being innovative. Then, we can match the experimental group and control group according to propensity score value. We use recently widely used nearest neighbor matching method inside the caliper to search and match the noninnovative enterprises whose score is the most close to the innovative enterprises in a given range of the caliper of $\varepsilon \leq 0.25 \hat{\sigma}_{p}$. After complete matching, there will be no differences between the matching variables of the experimental group and control group. So, the survival duration $E\left\{\right.$ Time $_{i t}^{0} \mid$ Creation $\left._{i t}=0\right\}$ of the enterprises without innovative behavior can be used as the replacement of $E\left\{\mathrm{Time}_{i t}^{0} \mid \mathrm{Creation}_{i t}=1\right\}$, the survival time of an innovative enterprise before innovation. At this point, the only difference left between the control group and experimental group is the innovative behavioral difference.

\section{The Cox risk model}

Cox model has obvious advantages in analyzing the data with a long duration, able to skillfully incorporate enterprises' survival time with whether to withdraw from the market. As to the question of the right merge, the Cox model builds a virtual variable to record and check whether the observation cycle of individual enterprise $i$ is complete. At the end of the study period, it is designated that the value of enterprises still surviving in the market is 0 and enterprise samples with a complete observation cycle 1. Through the enterprises' hazard function, the distribution of the enterprises' survival time is estimated, and the probability for the enterprise to exit the market in the future is predicted. This way can we solve the problem of special right merger that the data with a long duration is unable to avoid. 
Assume that enterprises face various risk of exiting the market in the process of continued operation, and its risk function in period $t$ is $\lambda(t ; x)$, the risk function can be decomposed into:

$$
\lambda(t ; x)=\lambda_{0}(t) e^{x^{\prime} \beta}
$$

In this formula, $\lambda_{0}(t)$ is the baseline hazard function, which is exactly the same for each sample enterprise, independent from the differences among enterprises but only being affected by the factor of time. $e^{x^{\prime} \beta}$ is the relative risk of the enterprises, $x$ is the assembly of concomitant variables, while $\beta$ is the assembly of parameter variables $x$ $=\left(x_{1}, x_{2}, \ldots, x_{n}\right)$. This formula means that for each increase of a unit in $x$, new risk rate will be the original $e^{\beta}$.

Suppose there are two types of enterprises: $i$ and $j$ whose assembly of covariant are $x_{i}{ }^{\prime}$ and $x_{j}{ }^{\prime}$, then the ratio of risk function of enterprise $i$ and $j$ is

$$
\frac{\lambda\left(t ; x_{i}^{\prime}\right)}{\lambda\left(t ; x_{j}^{\prime}\right)}=\frac{\lambda_{0}(t) e^{x_{i}{ }^{\prime} \beta}}{\lambda_{0}(t) e^{x_{j}^{\prime} \beta}}=e^{\left(x^{i}-x^{j}\right)^{\prime} \beta}
$$

Obviously, the ratio between the risk functions of enterprise $i$ and $j$ will not change as time passes but only relates to $x_{i}-x_{j}$. This enables us to estimate $\beta$ even without designating the concrete function form for baseline hazard function $\lambda_{0}(t)$. Specifically, in this study, the risk function of innovative enterprises can be illustrated as $\lambda\left(t ; x_{\text {Creation }=1}\right) / \lambda\left(t ; x_{\text {Creation }=0}\right)=e^{(\Delta x)^{\prime} \beta}$. We can estimate the assembly of each covariant coefficient $\beta$, through partial likelihood estimate.

Referring to the driving factor of enterprises' survival probability estimated from Cefis and Marsili (2005) transition probability matrix and combining with the special institutional factors related to Chinese enterprises' entering and exit, we select the following indicators as a measure of China's enterprise survival risk covariant.

\section{Return on sales (profit)}

Profit is the most fundamental power for enterprises to enter and exit the market. For free access to exit the market, low profit or failure to gain profit or even continuous loss will drain enterprises to gradual death, which can be measured by the ratio between operating profit and sales revenue.

\section{The scale of enterprises (size)}

On the one hand, large enterprises can achieve economies of scope and economies of scale, in order to reduce the production cost of the products; on the other hand, large enterprises will transfer the signal of high-quality products to consumers, thus increasing the products' premium capability. These two aspects can improve the enterprises' survival ability which can be measured by logarithmic of enterprise sales deflating by the producer price index of 2000.

\section{The age limit of enterprises' setting up (age)}

It is believed in literature proposing the view of first-mover advantage that enterprises entering the market in an earlier time period would own survival advantage than those later comers by gaining first-mover advantage in an relatively earlier time period (Kim 
and Lee 2011). This can be measured by the formula in which the year of sample observation minuses the year of the enterprises' setting up and then plus 1.

\section{Business productivity (TFP)}

The lessons from Wei and Miaojie (2012) can be drawn and Olley and Pakes (1996) method can also be used to measure the productivity of the enterprise.

\section{Export intensity (export)}

There has been an empirical study showing that the relationship between export strength and enterprises' survival probability appears to be inverted " $U$ " shaped. When export strength is low, the increasing export strength lowers the risk of an enterprise. But when the export strength exceeds a "threshold," export intensity would reduce the enterprises' survival time (Jiao et al. 2015), which can be measured by the ratio of export delivery value and sales (Chen et al. 2013).

\section{Financing constraints (finance)}

This can be measured by the ratio between the differentials gained by liquid assets' deducting liquid liability and total assets (Chen et al. 2013).

\section{Ownership types (owner)}

With special institutional background in China, as the exit mechanism is not perfect, a large number of state-owned enterprises exist in the form of continuing losses rather than directly exiting from the market. We have introduced a virtual variable to measure the factors of corporate ownership, designating state-owned enterprises' value as 1 and non-state-owned enterprises' as 0.

In addition, we also took control of the fixed effects from the perspectives of industry, year, and region (Du et al. 2012). (1) Industrial dummy variable: establishes dummy variables in two-dimension code industry to control heterogeneity among industries; (2) year variables (year): used to control the change of time and other macroeconomic factors; (3) regional virtual variables (area): to build a binary virtual variable to control the difference on survival risk between coastal area and inland area. Set the value of enterprises in coastal regions as 1 and those not as 0 . Here, the coastal areas include a total of eight regions, namely, Shanghai, Zhejiang, Jiangsu, Beijing, Shandong, Jiangsu, Fujian, and Guangdong. The rest of the 23 areas belong to inland areas.

The descriptive statistics of main variables is as shown in Table 3.

\section{Result and discussion}

\section{Results of propensity score matching}

We find non-innovative enterprises whose score is the most close to the innovative enterprises within the scope of a quarter of the caliper of standard deviation of propensity score matching $-\left(\varepsilon \leq 0.25 \hat{\sigma}_{p}\right)$. In order to ensure the reliability of the matching results, we test the matching results from two aspects-mutual support hypothesis and balance hypothesis. The fulfillment of mutual support means that the distribution form of propensity score between experimental group and control group is nearly the same. By comparing nuclear density distribution characteristics before and after the matching of the experimental group and control group, we find that after a match, the nuclear 
Table 3 The descriptive statistics of main variables

\begin{tabular}{llrrrc}
\hline Name of variables & Symbol & Average & Minimum & Maximum & Standard deviation \\
\hline Return on sales & Profit & 0.061 & -1.000 & 1.000 & 0.191 \\
Enterprises' size & Size & 9.866 & 3.714 & 17.275 & 1.223 \\
Age limit of the enterprises' establishment & Age & 5.329 & 1.000 & 8.000 & 1.785 \\
Enterprises' productivity & TFP & 501.006 & 0.072 & 84607.480 & 1767.674 \\
Export intensity & Export & 0.0675 & 0.000 & 1.000 & 0.215 \\
Financial restraints & Finance & 0.067 & 0.000 & 1.000 & 0.215 \\
Ownership type & Owner & 0.053 & 0.000 & 1.000 & 0.224 \\
Capital intensity & Capital & 9.934 & 0.000 & 19.011 & 1.642 \\
Human capital & Resource & 0.346 & 0.000 & 1.000 & 0.247 \\
Asset-liability ratio & Debt & 0.853 & 0.000 & 1.000 & 0.158 \\
\hline
\end{tabular}

distribution features of control group and experimental group changes from original low correlation to almost the same. As a result, we can conclude that matching the effective mutual support assumptions are met and matching process significantly improves the distribution deviation of propensity score of the experimental group and control group.

Test hypothesis of matching balance requires to meet Creation $_{i} \perp X_{i} \mid P\left(X_{i}\right)$ after the match. This means that in the case of a given figure " $P\left(X_{i}\right)$ " of probability of enterprises' innovation, enterprises' innovative behavior and the covariant are independent from each other. We can examine the effects of matching balance by standard deviation. Standard deviation reflects the difference in the characteristics of variables' distribution among groups. The smaller the value is, the difference will be. If the absolute value of the standard deviation is less than 20 , we can think that the matching results are ideal. Table 4 reports the test results of the balance among matching variables. It can be found in Table 4 that the vast majority of the absolute value of the standard deviation after the match is less than $5 \%$. That means matching results meet the symmetry hypothesis. As a result, we can consider the matching variable selection as reasonable and matching results reliable. It should be pointed out that propensity score matching only controls the problem of measurable variables selection but can hardly solve the invisible deviation brought by unobservable variables.

\section{The innovative tendency and enterprise survival risk}

After finishing matching effectively, we will estimate the survival risk of 39,762 sample enterprises by the Cox model. The first question to be answered is whether the enterprises' innovative tendency significantly reduces their survival risk. Therefore, virtual variables of enterprises' innovation (INNOV) should be introduced. If a certain new product's output value of an enterprise is greater than zero, then the value will be set as 1 ; otherwise, the value would be 0 . It is important to note that $\lambda(t ; x)=\lambda_{0}(t) e^{x^{\prime} \beta}$ is an important assumption in the Cox model. If this assumption is inconsistent, the Cox model would not be used. Before empirical estimates are made, therefore, there is a need to set up and testify the model for data of long durations. This test is done with $\mathrm{PH}$ hypothesis which is on the basis of residual-based test whose purpose is to calculate enfield residuals of various explanatory variables and then conduct regression of time 
Table 4 Test on the balance of matching variables

\begin{tabular}{|c|c|c|c|c|c|c|}
\hline & \multirow[t]{2}{*}{ Samples } & \multicolumn{2}{|l|}{ Average } & \multirow{2}{*}{$\begin{array}{l}\text { Standard } \\
\text { deviation (\%) }\end{array}$} & \multirow{2}{*}{$\begin{array}{l}\text { Decrease range } \\
\text { of standard } \\
\text { deviation (\%) }\end{array}$} & \multirow{2}{*}{$\begin{array}{l}\text { Value } \\
\text { of } T\end{array}$} \\
\hline & & experimental group & control group & & & \\
\hline \multirow[t]{2}{*}{ Size } & Before matching & 8.866 & 8.204 & 44.28 & 99.2 & 14.73 \\
\hline & After matching & 8.866 & 8.853 & 0.3 & & 0.57 \\
\hline \multirow[t]{2}{*}{ TFP } & Before matching & 6.161 & 5.832 & 30.4 & 97.6 & 21.47 \\
\hline & After matching & 6.161 & 6.138 & 2.5 & & 1.38 \\
\hline \multirow[t]{2}{*}{ Finance } & Before matching & 1.133 & 1.285 & -12.7 & 50.3 & -8.31 \\
\hline & After matching & 1.133 & 1.126 & 3.2 & & 2.44 \\
\hline \multirow[t]{2}{*}{ Capital } & Before matching & 0.964 & 0.739 & 25.9 & 85.7 & 11.38 \\
\hline & After matching & 0.964 & 0.955 & 1.8 & & 0.87 \\
\hline \multirow[t]{2}{*}{ Profit } & Before matching & 3.624 & 2.172 & 60.2 & 99.8 & 30.16 \\
\hline & After matching & 3.624 & 3.486 & 6.4 & & 2.81 \\
\hline \multirow[t]{2}{*}{ Resource } & Before matching & 0.396 & 0.335 & 5.2 & 46.7 & 2.33 \\
\hline & After matching & 0.396 & 0.391 & 0.6 & & 0.05 \\
\hline \multirow[t]{2}{*}{ Export } & Before matching & 0.160 & 0.138 & 8.4 & 97.4 & 3.61 \\
\hline & After matching & 0.160 & 0.168 & -1.5 & & -0.52 \\
\hline \multirow[t]{2}{*}{ Debt } & Before matching & 0.572 & 0.541 & 10.3 & 89.3 & 4.28 \\
\hline & After matching & 0.572 & 0.570 & 0.4 & & 0.08 \\
\hline
\end{tabular}

parameter through residues in order to test whether the estimated time coefficient is zero or near zero. The test results of testing residual variables show that the time coefficients estimated by different residual errors is less than 0.003 , indicating that setting of the Cox model is reasonable.

Table 5 reports the inspection results of innovation tendency on enterprises' survival risk. It is important to note that our report focus on the risk ratios (hazard ratios) between the innovative enterprises against non-innovative enterprises, that is the index from of estimated coefficient. Risk ratio, less than 1, indicates that the variable will reduce the innovative enterprisess' survival risk; equal to 1 , indicates that the explanatory variables exert equal influence on both innovative and non-innovative enterprises in terms of survival risk; greater than 1 , shows the explanatory variables can increase innovative enterprises' survival risk. Column (1) controls the variables related to enterprises' characteristics, while column (2) further controls the regional effects, trade effects, and the year effect. Comparison of the results of column (1) and (2) would enable us to find that after controlling factors outside the enterprise internal control characteristics, there comes an increase in logarithmic likelihood value in the Cox model, that is, the explanatory power of the model increases. This means that the Chinese enterprises' survival risk is not only affected by its own internal characteristics but also by the industry characteristics, the macroscopic characteristics, or even regional environment. In terms of the variables of innovative tendency, their risk proportions in the first columns (1) and (2) were significantly less than 1 , showing that the enterprises' survival risk of experimental group is significantly lower than that of the control group. This implies that innovative activities can lower the enterprises' survival risk in the market, and improve enterprises' survival time in the market. Innovative enterprises' survival risk is about 11 13\% less than that of the innovative enterprises. This conclusion 
Table 5 The test result of the innovative tendency on enterprises' survival risk

\begin{tabular}{|c|c|c|c|c|c|c|c|}
\hline \multirow[t]{2}{*}{ Explanatory variables } & \multicolumn{3}{|c|}{ Cox model (index regression) } & \multicolumn{2}{|c|}{ Cloglog model } & \multicolumn{2}{|c|}{$\begin{array}{l}\text { Samples of non-state- } \\
\text { owned enterprises }\end{array}$} \\
\hline & (1) & (2) & (3) & (4) & (5) & (6) & (7) \\
\hline INNOV & $\begin{array}{l}0.890^{\mathrm{a}} \\
(0.013)\end{array}$ & $\begin{array}{l}0.876^{a} \\
(0.028)\end{array}$ & $\begin{array}{l}0.851^{a} \\
(0.029)\end{array}$ & $\begin{array}{l}0.876^{a} \\
(0.028)\end{array}$ & $\begin{array}{l}0.875^{a} \\
(0.030)\end{array}$ & $\begin{array}{l}0.855^{\mathrm{a}} \\
(0.030)\end{array}$ & $\begin{array}{l}0.853^{a} \\
(0.029)\end{array}$ \\
\hline C & $\begin{array}{l}0.520^{\mathrm{a}} \\
(0.015)\end{array}$ & $\begin{array}{l}0.404^{\mathrm{a}} \\
(0.013)\end{array}$ & $\begin{array}{l}0.388^{\mathrm{a}} \\
(0.012)\end{array}$ & $\begin{array}{l}0.402^{\mathrm{a}} \\
(0.013)\end{array}$ & $\begin{array}{l}0.406^{\mathrm{a}} \\
(0.013)\end{array}$ & $\begin{array}{l}0.496^{\mathrm{a}} \\
(0.015)\end{array}$ & $\begin{array}{l}0.473^{\mathrm{a}} \\
(0.015)\end{array}$ \\
\hline Profit & $\begin{array}{l}0.964 \\
(0.128)\end{array}$ & $\begin{array}{l}0.966 \\
(0.128)\end{array}$ & $\begin{array}{l}0.964 \\
(0.128)\end{array}$ & $\begin{array}{l}0.966 \\
(0.128)\end{array}$ & $\begin{array}{l}0.956 \\
(0.124)\end{array}$ & $\begin{array}{l}0.958 \\
(0.124)\end{array}$ & $\begin{array}{l}0.963 \\
(0.123)\end{array}$ \\
\hline Size & $\begin{array}{l}0.759^{\mathrm{a}} \\
(0.028)\end{array}$ & $\begin{array}{l}0.656^{\mathrm{a}} \\
(0.003)\end{array}$ & $\begin{array}{l}0.659^{\mathrm{a}} \\
(0.028)\end{array}$ & $\begin{array}{l}0.682^{b} \\
(0.003)\end{array}$ & $\begin{array}{l}0.731^{b} \\
(0.025)\end{array}$ & $\begin{array}{l}0.754^{\mathrm{a}} \\
(0.025)\end{array}$ & $\begin{array}{l}0.752^{\mathrm{a}} \\
(0.003)\end{array}$ \\
\hline Age & $\begin{array}{l}0.921^{\mathrm{a}} \\
(0.018)\end{array}$ & $\begin{array}{l}0.833^{\mathrm{a}} \\
(0.017)\end{array}$ & $\begin{array}{l}0.832^{\mathrm{a}} \\
(0.017)\end{array}$ & $\begin{array}{l}0.875^{b} \\
(0.017)\end{array}$ & $\begin{array}{l}0.844^{b} \\
(0.017)\end{array}$ & $\begin{array}{l}0.882^{\mathrm{a}} \\
(0.020)\end{array}$ & $\begin{array}{l}0.882^{\mathrm{a}} \\
(0.020)\end{array}$ \\
\hline TFP & $\begin{array}{l}0.888^{\mathrm{a}} \\
(0.004)\end{array}$ & $\begin{array}{l}0.873^{\mathrm{a}} \\
(0.004)\end{array}$ & $\begin{array}{l}0.888^{\mathrm{a}} \\
(0.004)\end{array}$ & $\begin{array}{l}0.873^{\mathrm{a}} \\
(0.004)\end{array}$ & $\begin{array}{l}0.897^{c} \\
(0.004)\end{array}$ & $\begin{array}{l}0.846^{\mathrm{a}} \\
(0.004)\end{array}$ & $\begin{array}{l}0.842^{\mathrm{a}} \\
(0.004)\end{array}$ \\
\hline Export & $\begin{array}{l}0.894 \\
(0.006)\end{array}$ & $\begin{array}{l}0.879 \\
(0.006)\end{array}$ & $\begin{array}{l}0.883 \\
(0.006)\end{array}$ & $\begin{array}{l}0.873 \\
(0.006)\end{array}$ & $\begin{array}{l}0.868 \\
(0.006)\end{array}$ & $\begin{array}{l}0.891 \\
(0.006)\end{array}$ & $\begin{array}{l}0.892 \\
(0.006)\end{array}$ \\
\hline Finance & $\begin{array}{l}0.854 \\
(0.017)\end{array}$ & $\begin{array}{l}0.831^{c} \\
(0.017)\end{array}$ & $\begin{array}{l}0.830^{c} \\
(0.017)\end{array}$ & $\begin{array}{l}0.831^{\mathrm{C}} \\
(0.017)\end{array}$ & $\begin{array}{l}0.830 \\
(0.017)\end{array}$ & $\begin{array}{l}0.868^{c} \\
(0.016)\end{array}$ & $\begin{array}{l}0.865 \\
(0.016)\end{array}$ \\
\hline Owner & $\begin{array}{l}0.637^{a} \\
(0.022)\end{array}$ & $\begin{array}{l}0.614^{a} \\
(0.023)\end{array}$ & $\begin{array}{l}0.602^{a} \\
(0.022)\end{array}$ & $\begin{array}{l}0.614^{a} \\
(0.023)\end{array}$ & $\begin{array}{l}0.602^{\mathrm{a}} \\
(0.023)\end{array}$ & $\begin{array}{l}0.627^{\mathrm{a}} \\
(0.023)\end{array}$ & $\begin{array}{l}0.605^{a} \\
(0.021)\end{array}$ \\
\hline Profit $^{\mathrm{C}}$ INNOV & & & $\begin{array}{l}0.970 \\
(0.113)\end{array}$ & & $\begin{array}{l}0.947 \\
(0.108)\end{array}$ & & $\begin{array}{l}0.925 \\
(0.110)\end{array}$ \\
\hline Size ${ }^{c}$ INNOV & & & $\begin{array}{l}0.933^{\mathrm{a}} \\
(0.016)\end{array}$ & & $\begin{array}{l}0.916^{c} \\
(0.015)\end{array}$ & & $\begin{array}{l}0.927^{\mathrm{a}} \\
(0.016)\end{array}$ \\
\hline Age $^{c}$ INNOV & & & $\begin{array}{l}0.821^{\mathrm{b}} \\
(0.007)\end{array}$ & & $\begin{array}{l}0.802^{c} \\
(0.007)\end{array}$ & & $\begin{array}{l}0.814^{\mathrm{b}} \\
(0.007)\end{array}$ \\
\hline TFPC INNOV & & & $\begin{array}{l}0.870^{c} \\
(0.015)\end{array}$ & & $\begin{array}{l}0.866^{c} \\
(0.015)\end{array}$ & & $\begin{array}{l}0.861^{\mathrm{c}} \\
(0.014)\end{array}$ \\
\hline Export ${ }^{C}$ INNOV & & & $\begin{array}{l}0.837 \\
(0.039)\end{array}$ & & $\begin{array}{l}0.835 \\
(0.039)\end{array}$ & & $\begin{array}{l}0.830 \\
(0.038)\end{array}$ \\
\hline Finance $^{c}$ INNOV & & & $\begin{array}{l}1.014^{\mathrm{b}} \\
(0.047)\end{array}$ & & $\begin{array}{l}1.006^{\mathrm{C}} \\
(0.047)\end{array}$ & & $\begin{array}{l}1.008^{c} \\
(0.042)\end{array}$ \\
\hline Owner ${ }^{c}$ INNOV & & & $\begin{array}{l}1.075 \\
(0.067)\end{array}$ & & $\begin{array}{l}1.244 \\
(0.067)\end{array}$ & & $\begin{array}{l}1.072 \\
(0.071)\end{array}$ \\
\hline Industry & No & Yes & Yes & Yes & Yes & Yes & Yes \\
\hline Year & No & Yes & Yes & Yes & Yes & Yes & Yes \\
\hline Area & No & Yes & Yes & Yes & Yes & Yes & Yes \\
\hline Log likelihood & $-112,184.31$ & $-99,372.26$ & $-99,464.77$ & $-99,388.21$ & $-99,361.93$ & $-98,471.88$ & $-98,463.69$ \\
\hline Number of samples & 184,282 & 184,282 & 184,282 & 184,282 & 184,282 & 123,061 & 123,061 \\
\hline Rho value & & & & 0.164 & 0.168 & & \\
\hline $\begin{array}{l}\text { Likelihood ratio test of } \\
\text { rho value }\end{array}$ & & & & $\begin{array}{l}150.31 \\
(0.128)\end{array}$ & $\begin{array}{l}148.76 \\
(0.111)\end{array}$ & & \\
\hline
\end{tabular}

Note: ${ }^{\mathrm{a}}, \mathrm{b}$, and ${ }^{\mathrm{c}}$ on 1,5 , and $10 \%$ levels, respectively, in parentheses for standard error; said "yes" to control industry, region, and year, instead of "no". Sample size indicate measurements, not the number of individual enterprises

verifies the efficacy of the micro approach of present innovation-driven development strategy formulated by the Chinese government.

Among the internal characteristics influencing the enterprises' survival, the survival risk of state-owned enterprises is significantly lower than that of non-state-owned enterprises. Such conclusion is in line with expectations, for most of the state-owned enterprises are not expelled out of the market on account of continuous losses or no 
earnings expectations but due to policy factors. Therefore, we can see a phenomenon that a large number of state-owned enterprises are surviving in the form of loss in the market. Enterprises' size, age, and productivity are negatively related to the innovation enterprises' survival risk, which means that the large-scale enterprises with high productivity of can take advantage in economies of scale, efficiency, and ability to resist risks, all of which have reduced the enterprises' risk in the market (Tsvetkova et al. 2014; Manjon-Antolın and Arauzo-Carod 2008; Jensen et al. 2008). Old enterprises' survival risk, significantly lower than that of young enterprises, would show that there is inertia in old enterprises, increasing the difficulty of the "search matching" and incurring an unavoidable question of survival risk concentration. Extent of financing constraints is positively related to enterprises' survival risk, associated with the degree of, which means to alleviate Chinese enterprises' financing constraints, meaning that easing financial constraints of Chinese enterprises helps to extend the survival time of enterprises (Yuduo et al. 2014). What needs to be pointed out is that profitability and foreign trade do not significantly reduce enterprises' survival risk. Instead, the more enterprises rely on export, the bigger enterprises' survival risk is. This conclusion is vastly different from existing literature (Esteve and Ssanchis-Llopis 2010; Tsvetkova et al. 2014).The possible reason is that there is a large amount of zombies in the market. Due to the reason of the administrative system, the profitability of zombie companies is very poor, but the firms do not face the risk of exiting the market, that is to say, the presence of these zombie companies may interfere with the effects of profit ability of survival risk.

For further inspection of the influence of innovative activities on the internal mechanism of enterprises' survival risk, we added the innovation tendency to interact with the enterprises' characteristic variables, which can be seen reported in column (3). It can be found in the seven interactive items that enterprises' size, age, financing constraints, productivity, and innovative tendency all boast the level of $10 \%$ and pass the test. The risk ratio coefficient between innovative tendency and the enterprises' scale is significantly less than 1 , which suggests that innovative behavior will help increase the survival time of scale enterprises. Such is particularly apparent in the survival incremental effect of the large enterprises. The interaction ratio coefficient of innovation tendency against enterprises' age is significantly less than 1, which suggests that innovative activities help ease agglomeration of the survival risk of those enterprises established long time ago. The conclusion of the two interactive items is consistent with the research conclusions drawn by Cefis and Marsili (2005). The ratio coefficient of the interactive items of innovative tendency against the business productivity, significantly less than 1 , suggests that enterprises with high productivity can get more enduring survival time by adjustment on innovation.

It is worth noting that when the risk ratio coefficient of interactive items between financing constraints and innovative behavior is greater than 1, innovative behavior would accelerate the accumulation of risks of financing constraints, thus enterprises with financing constraints should not do any innovative activities. The possible reason is that innovative process requires considerable investment and undertake huge risk (Chuntao and Min 2015). Once the innovative activities can not be transferred into income in a short period, coupled with the huge restraints for enterprises in the financing channels and methods, enterprises' cash flow will appear a lot of problems that may 
increase their probability of withdrawing from market. Therefore, for enterprises whose financing is rather limited, we should carefully choose the inputs in innovative activities. This conclusion reflects the dilemma Chinese companies experience at this stage. Especially for small- and medium-sized enterprises, they have faced financing difficulties of "uneasy and expensive financing," such as high threshold, unitary ways, narrow channels, high cost, and the huge funding gap. Under such background of the financing constraints, small- and medium-sized enterprises generally do not choose to make investment in the risky innovative activities, for their innovative impetus is insufficient. In addition, return on sales, export intensity ownership type, and interactive items of innovative behaviors failed to pass the test of significance, suggesting that the profit ability, export intensity, and differences on ownership can exert adjustment on survival time.

To test the estimation robustness, on the one hand, we refer to the method conducted by Qilin and Jiayun (2015) and adopt Clog log discrete-time survival model to estimate successful matching data. Figures from (4) and (5) report the estimated results in the case of no interaction and with interactive items. Likelihood ratio test of Rho value with two results has accepted original hypothesis of the unobservable heterogeneity. Therefore, this is a further sign of the Cox model design's reasonability; on the other hand, considering the particularity of state-owned enterprises' survival time, we extract the samples from the database of all the non-state enterprises, estimate once again with the abovementioned method and the Cox model, and gain the results of (6) and (7). Such test results show that the estimated results have very strong robustness. In addition, we further use Weibull regression to further broaden the value of assumed risk function in index regression, only to find that there is no obvious fluctuations in inspection results.

\section{The release effect of innovation intensity on the enterprises' survival risk}

It has been mentioned that samples are divided into experimental group and control group on the basis of innovation tendency. It has been demonstrated relatively logically that the innovative activities can inhibit the enterprise survival risk. What needs to be pointed out is that this merely reflects the average effect of innovation to the enterprise survival risk. In fact, as some entrepreneurs and scholars concern, while innovation produces "creative destruction" in the dynamics of the industry, the cost of innovation also is significant as an important item of enterprises' spending. In general, the enterprise will not make innovation investment without reservation. Otherwise, the enterprises' cash flow will be tightened with gathered risk.

Next, it is necessary for us to explore some questions. What is the appropriate level for innovation strength? What is the optimal innovation strength level for enterprise survival? To answer these questions, we first define the strength of innovation. Innovation strength (INTEN) is defined as the ratio of enterprises' new products production against sales and deflates in accordance with the producer price index in 2000. Then, for a more detailed analysis on the heterogeneity effect of innovation strength on the enterprises' survival risk, we order the innovation intensity from low to high and classify the samples as per as quartile into four segments (INTENi, $I=1,2,3,4$ ) -weak innovation strength group INTEN1 [0, 25\%), medium innovation strength group 
INTEN2 [25, 50\%), strong innovation strength group INTEN3 [50, 75\%), and the strongest innovation strength group INTEN4 [75, 100\%). So, heterogeneity effect of the enterprise survival risks can be observed by comparing the size of the estimated coefficient.

Table 6 reports the estimated results of innovative intensity under different quantile intensities. Comparing the estimated results in the above, we have controlled the differences of enterprises' internal and external characteristics. Column (1) is the regression result of the whole experimental group. The test results show that there is negative correlation between the strength of innovation and enterprises' survival risk. on average, every increase unit of $R \& D$ intensity can make enterprise survive in market risk by $28.3 \%$.

Table 6 Heterogeneity effect of innovation intensity on enterprises' survival risk

\begin{tabular}{|c|c|c|c|c|c|c|c|}
\hline \multirow[t]{2}{*}{ Explanatory variables } & \multicolumn{3}{|c|}{ Cox model (index regression) } & \multicolumn{2}{|c|}{ Cloglog model } & \multicolumn{2}{|c|}{$\begin{array}{l}\text { Samples of non-state- } \\
\text { owned enterprises }\end{array}$} \\
\hline & (1) & (2) & (3) & (4) & (5) & (6) & (7) \\
\hline INTEN & $\begin{array}{l}0.717^{a} \\
(0.019)\end{array}$ & & & $\begin{array}{l}0.719^{a} \\
(0.019)\end{array}$ & & $\begin{array}{l}0.702^{a} \\
(0.018)\end{array}$ & \\
\hline INTEN $^{2}$ & & & $\begin{array}{l}1.091^{b} \\
(0.028)\end{array}$ & & & & \\
\hline INTEN $_{1}$ & & $\begin{array}{l}0.825^{\mathrm{a}} \\
(0.012)\end{array}$ & & & $\begin{array}{l}0.813^{\mathrm{a}} \\
(0.012)\end{array}$ & & $\begin{array}{l}0.846^{\mathrm{a}} \\
(0.012)\end{array}$ \\
\hline INTEN $_{2}$ & & $\begin{array}{l}0.664^{\mathrm{a}} \\
(0.018)\end{array}$ & & & $\begin{array}{l}0.636^{\mathrm{a}} \\
(0.018)\end{array}$ & & $\begin{array}{l}0.652+a \\
(0.018)\end{array}$ \\
\hline INTEN $_{3}$ & & $\begin{array}{l}0.798^{c} \\
(0.020)\end{array}$ & & & $\begin{array}{l}0.763^{c} \\
(0.024)\end{array}$ & & $\begin{array}{l}0.781^{b} \\
(0.018)\end{array}$ \\
\hline $\mathrm{INTEN}_{4}$ & & $\begin{array}{l}0.913 \\
(0.103)\end{array}$ & & & $\begin{array}{l}0.911 \\
(0.102)\end{array}$ & & $\begin{array}{l}0.917 \\
(0.109)\end{array}$ \\
\hline Profit & $\begin{array}{l}0.934 \\
(0.125)\end{array}$ & $\begin{array}{l}0.936 \\
(0.125)\end{array}$ & $\begin{array}{l}0.937 \\
(0.125)\end{array}$ & $\begin{array}{l}0.931 \\
(0.122)\end{array}$ & $\begin{array}{l}0.931 \\
(0.122)\end{array}$ & $\begin{array}{l}0.925 \\
(0.128)\end{array}$ & $\begin{array}{l}0.924 \\
(0.128)\end{array}$ \\
\hline Size & $\begin{array}{l}0.768^{\mathrm{a}} \\
(0.003)\end{array}$ & $\begin{array}{l}0.754^{\mathrm{a}} \\
(0.003)\end{array}$ & $\begin{array}{l}0.768^{a} \\
(0.003)\end{array}$ & $\begin{array}{l}0.732^{a} \\
(0.002)\end{array}$ & $\begin{array}{l}0.726^{a} \\
(0.002)\end{array}$ & $\begin{array}{l}0.754^{\mathrm{a}} \\
(0.003)\end{array}$ & $\begin{array}{l}0.748^{a} \\
(0.003)\end{array}$ \\
\hline Age & $\begin{array}{l}0.817^{\mathrm{a}} \\
(0.018)\end{array}$ & $\begin{array}{l}0.815^{\mathrm{a}} \\
(0.018)\end{array}$ & $\begin{array}{l}0.817^{\mathrm{a}} \\
(0.018)\end{array}$ & $\begin{array}{l}0.843^{\mathrm{a}} \\
(0.018)\end{array}$ & $\begin{array}{l}0.840^{\mathrm{a}} \\
(0.018)\end{array}$ & $\begin{array}{l}0.891^{\mathrm{a}} \\
(0.019)\end{array}$ & $\begin{array}{l}0.888^{a} \\
(0.019)\end{array}$ \\
\hline TFP & $\begin{array}{l}0.691^{\mathrm{a}} \\
(0.004)\end{array}$ & $\begin{array}{l}0.680^{\mathrm{a}} \\
(0.004)\end{array}$ & $\begin{array}{l}0.680^{\mathrm{a}} \\
(0.004)\end{array}$ & $\begin{array}{l}0.703^{\mathrm{a}} \\
(0.003)\end{array}$ & $\begin{array}{l}0.703^{\mathrm{a}} \\
(0.003)\end{array}$ & $\begin{array}{l}0.682^{\mathrm{a}} \\
(0.004)\end{array}$ & $\begin{array}{l}0.682^{a} \\
(0.004)\end{array}$ \\
\hline Export & $\begin{array}{l}0.927 \\
(0.009)\end{array}$ & $\begin{array}{l}0.925 \\
(0.009)\end{array}$ & $\begin{array}{l}0.925 \\
(0.009)\end{array}$ & $\begin{array}{l}0.942 \\
(0.010)\end{array}$ & $\begin{array}{l}0.942 \\
(0.010)\end{array}$ & $\begin{array}{l}0.931 \\
(0.010)\end{array}$ & $\begin{array}{l}0.933 \\
(0.010)\end{array}$ \\
\hline Finance & $\begin{array}{l}0.823^{c} \\
(0.016)\end{array}$ & $\begin{array}{l}0.823^{c} \\
(0.016)\end{array}$ & $\begin{array}{l}0.828^{c} \\
(0.015)\end{array}$ & $\begin{array}{l}0.864 \\
(0.014)\end{array}$ & $\begin{array}{l}0.864 \\
(0.014)\end{array}$ & $\begin{array}{l}0.831^{c} \\
(0.015)\end{array}$ & $\begin{array}{l}0.831^{c} \\
(0.015)\end{array}$ \\
\hline Owner & $\begin{array}{l}0.615^{\mathrm{a}} \\
(0.021)\end{array}$ & $\begin{array}{l}0.618^{\mathrm{a}} \\
(0.022)\end{array}$ & $\begin{array}{l}0.612^{\mathrm{a}} \\
(0.021)\end{array}$ & $\begin{array}{l}0.620^{\mathrm{a}} \\
(0.023)\end{array}$ & $\begin{array}{l}0.620^{\mathrm{a}} \\
(0.023)\end{array}$ & $\begin{array}{l}0.601^{\mathrm{a}} \\
(0.020)\end{array}$ & $\begin{array}{l}0.601^{a} \\
(0.020)\end{array}$ \\
\hline Industry & Yes & Yes & Yes & Yes & Yes & Yes & Yes \\
\hline Year & Yes & Yes & Yes & Yes & Yes & Yes & Yes \\
\hline Area & Yes & Yes & Yes & Yes & Yes & Yes & Yes \\
\hline Log likelihood & $-92,184.31$ & $-91,463.26$ & $-91,632.53$ & $-91,768.66$ & $-91,226.90$ & $-91,242.98$ & $-91,488.21$ \\
\hline Quantity of samples & 184,282 & 184,282 & 184,282 & 184,282 & 184,282 & 123,061 & 123,061 \\
\hline Rho value & & & & 0.146 & 0.142 & & \\
\hline $\begin{array}{l}\text { Likelihood ratio test of } \\
\text { Rhovalue }\end{array}$ & & & & $\begin{array}{l}130.77 \\
(0.153)\end{array}$ & $\begin{array}{l}151.26 \\
(0.138)\end{array}$ & & \\
\hline
\end{tabular}

Note: ${ }^{a},{ }^{b}$, and ${ }^{c}$ signify figures become apparent at the level of 1, 5, and $10 \%$. Inside the bracket is standard error; "Yes" means to control on industry, year, and region, while the negative means "No"; quantity of samples signify the observed value instead of the number of individual enterprises 
Column (2) is an estimated result of segmented experimental group differentiated by the quartile. We can find that, on the one hand, the risk coefficient of INTEN1, INTEN2, and INTEN3 is significantly less than 1, and the absolute value of the three estimated coefficient presents the trend of decreasing after increasing first. Such results show that the influence of R \& D intensity to the enterprises' survival risk has nonstationary characteristics rather than proportional one-the stronger research and development is, the obvious its inhibition effect on enterprise risk will be. The relationship between innovation strength and enterprises' survival risk is like "inverted U," meaning the marginal contribution of inhibition effect is gradually reduced. On the other hand, the risk ratio of INTEN4 is less than 1 and does not own statistical significance. Such result shows the enterprises fully focusing on innovative activities will not reduce their risk of survival in the market significantly. That is to say, there is an optimal critical level suitable for the innovative enterprises' survival strength. There are two aspect reasons, on the one hand, the characteristics of high risk of innovative activities have made enterprises with innovation strength face survival risks of inadequate market demand and nervous cash flow in a given year. On the other hand, the intellectual property protection system of China is likely to lead to the enterprise innovation spillover. A large amount of firms can acquire innovations by imitation, learning, and even stealing. This conclusion proves partially that the fact that Chinese enterprises lack innovation power and would rather bear the risk of producing homogeneous products due to low price competition than undertake the risk of failure to innovate.

In order to ensure the reliability of innovation intensity to the enterprises' survival risk, this article has carried on the robustness test as follows: first, introduce quadratic term of innovative strength to further determine the non-equilibrium effect of innovation intensity on enterprises' survival risk; second, in order to further determine the rationality of the existence model usage Cloglog discrete-time survival model is introduced to make a second estimate; third, extract all the non-state enterprises' samples and estimate once again by using the above matching method and the Cox model. Estimated results from column (3) to column (7) show that the setting up and regression of the model have high robustness.

\section{Conclusions}

There is no denying on the fact that Chinese companies are not willing to make investment in innovation during the transition. This paper aims to reveal the inhibition effect of innovative activities on the enterprises' survival risk can prolong the survival time of enterprises. In particular, the targets include using micro-level data of China's industrial enterprises from 2000 to 2007 and investigate the innovative behavior's influence on enterprises' survival time by using quasi natural experiment design. Research results show that, first of all, the innovative enterprises have better ability to resist risk than non-innovative enterprises, as innovative activities release about $12 \%$ survival risk and can increase their survival time of 0.84 years. Each additional unit of the innovation strength can lower the risk of the survival of $28.3 \%$ on average, which verifies the efficacy of the micro approach towards enterprises' survival of present innovation-driven development strategy formulated by the Chinese government. Second, the inhibition effect of R\&D intensity to the enterprises' survival present non-stationary characteristics. When the R\&D intensity reaches a certain threshold, the inhibition effect of enterprise 
risk began to gradually decline; finally, the difference of the enterprises' internal characteristics will change the inhibition effect of innovation activity on survival risk. The incremental effect of innovative activities from large enterprises with high productivity is more apparent, as innovative activities help ease the survival risk agglomeration of enterprises established long time ago. Innovative behavior, however, will accelerate accumulation of risks from financing constraints, so enterprises with financing limit should not conduct innovative activities.

So, to reduce the enterprises' survival risk and increase the longevity of Chinese enterprises and given the conclusion of this article, the Chinese government endeavors to take measures in identifying the future direction of the industrial organization policy from the following several aspects: the first policy is industrial level measures, on the one hand, improve the enterprises' financing mechanism to make enterprise "dare" to make innovation. This paper concludes that companies with financing limit will accelerate the agglomeration of survival risk in the case of innovation. At present, smalland medium-sized enterprises are faced with the problems of financing difficulties of uneasy and expensive financing, narrow channels, and universal cowards for innovation. Therefore, only through perfecting enterprises' financing mechanism, alleviating the abovementioned enterprises' financing difficulties can enterprises be courageous to invest a lot of money on the innovative activities; on the other hand, improve the system of intellectual property protection to make enterprise "willing" for innovation. There is no denying on the fact that China's property rights protection system have a lot of defects including imitation and plagiarism, and Chinese enterprises' innovation premium rate is not high. Therefore, only enough homework is done in terms of the intellectual property system can enterprises' innovation have clear property rights, and increased innovation premium rate, while enterprises will be willing to engage in innovative activities. The second policy is incentive firms to engage in research and development activities. For example, the government can employ R\&D subsidies and tax incentives to encourage enterprises engaged in innovative activities.

Funding

The paper is supported by the ministry of education of humanities and social science fund (16YJC790001), Zhejiang provincial Project of Natural Science Fund (LY16G030014), and ZheJiang Provincial Project of Philosophy and Social Science(17NDJC177YB)

Competing interests

The authors declare that they have no competing interests.

Received: 2 September 2016 Accepted: 13 November 2016

Published online: 22 November 2016

References

Yong-bing C, yan L, Shi-min Z (2013) Export duration of China's enterprises and related determinants. Econ Res (6):7691.

Yan-ying C, Zongke B (2016) Market entry, age and innovation motivation. J Econ Manage Res 32(4):23-32.

Zhen C, Xue W (2014) The innovative behavior, sunk costs, and the enterprises' survival. Sci Technol Res (10):25-42.

Jianbai H, Bing B, Yu C (2010) An empirical study on the influence of enterprises' and industry's characteristics on enterprises' survival time in Hunan. Theory Pract Syst Eng 18(5):102-115.

Hui L (2013) Enterprise innovation incentive - the explanation for China's labor costs rise. Manage World (9):89-103

Yuduo L, Meshing D, Haiyang L (2014) Has the financing constraints reduced China's R\&D-oriented enterprises' survival probability? Sci Res 10:43-62.

Chuntao L, Min S (2015) China's manufacturing industrial enterprises' innovative activities: the role of ownership and CEO incentive. Econ Res (5):134-151.

Qilin M, Jiayun X (2015) Has the governmental subsidies inspired new product innovation? J China Ind Econ (12):55-73.

Qilin M, Bin S (2013) The enter and exit of Chinese manufacturing enterprises and dynamic evolution of productivity. Econ Res (4):33-48. 
Xingzhi X, Wentao H, Xiaodan G (2014) The accumulation, expansion behavior and continued survival of enterprises. Manage World (2):101-116.

Jiao Y, Yuduo L, Haiyang L (2015) Export behavior and enterprise survival probability: a study of experience. World Econ 4:(71-91).

Wei T, Miaojie Y (2012): The productivity of enterprises and enterprises' "going out": the foreign direct investment based on an empirical study on enterprise-level data, Economics (quarterly)

Audretsch DB (1995) Innovation, growth and survival. Int J of Ind Organ 13(4):441-457

Audretsch D, Mahmood T (1995) New firm survival: new results using a hazard function. Econ Lett 77(1):97-103

Bayus BL, Agarwal R (2007) The role of pre-entry experience, entry timing, and product technology. Access and Download Statistics 53(12):1887-1902

Buddelmeyer H, Jenseny PH, Webster E (2010) Innovation and the determinants of company survival. Oxf Econ Pap 62(2):261-285

Caves RE (1998) Industrial organization and new findings on the turnover and mobility of firms. J Econ Lit 36(4):1947-1982

Cefis E, Marsili O (2005) A matter of life and death: innovation and firm survival. Ind Corp Chang 14(6):1-26

Chen M, Guariglia A, Internal Financial Constraints and Firm Productivity in China (2013) Do liquidity and export behavior make a difference. J Comp Econ 41(4):1123-1140

Coad A, Segarra A, Teruel M (2010) Like milk or wine: does firm performance improve with age. Papers Econ Evol 24(1): 173-189

Du J, Lu Y, Tao Z, Yu L (2012) Do domestic and foreign exporters differ in learning by exporting? Evidence from China. China Econ Rev 23(2):296-315

Esteve PS, Ssanchis-Llopis JA (2010) A competing risks analysis of firms' exit. Empir Econ 38(2):281-304

Esteve PS, Mañez-Castillejo AJ (2008) The resource-based theory of the firm and firm survival. Small Business Economics 30(3):231-249

Fontana R, Nesta L (2009) Product innovation and survival in a high-tech industry. Rev Ind Organ 34(4):287-306

Geroski P (1995) What do we know about entry? Int J Ind Organ 13(4):421-440

Harhoff D, Narin F, Scherer FM, Vopel K (1999) Citation frequency and the value of patented inventions. Rev Econ Stat 81(3):511-515

Hopenhayn H (1992) Entry, exit, and firm dynamics in long run equilibrium. Econometrica 60(5):1127-1150

Jensen PH, Webster E, Buddelmeyer H (2008) Innovation, technological conditions and new firm survival. Econ Rec 84(267):434-448

Kim J, Lee CY (2011) Technological regimes and the persistence of first-mover advantages. Ind Corp Chang 20(5):1305-1333

Kleinknecht A, Van Montfort K, Brouwer E (2002) The non-trivial choice between innovation indicators. Econ J Innov New Technol 11(2):109-121

Manjon-Antolın MC, Arauzo-Carod JM (2008) Firm survival: methods and evidence. Empirica 35(1):1-24

Namini JE, Facchini G, Lopez RA (2013) Export growth and firm survival. Econ Lett 120(3):481-486

Ortega-Argiles R., \& Moreno R. (2005) Firm competitive strategies and the likelihood of survival: the Spanish case. Ersa Conference Paper

Olley GS, Pakes A (1996) The dynamics of productivity in the telecommunication equipment industry. Econometrica 64(6):1263-1297

Pakes A, Ericson R (1998) Empirical implications of alternative models of firm dynamics. J Econ Theory 79(1):1-45

Sivadas E, Dwyer RF (2000) An examination of organizational factors influencing new product development in internal and alliance-based processes. J Mark 64(1):31-49

Tripsas M, Gavetti G (2000) Capabilities, cognition, and inertia: evidence from digital imaging. Strateg Manag J 21(10): $1147-1161$

Tsvetkova A, Thill JC, Strumsky D (2014) External effects of metropolitan innovation on firm survival: non-parametric evidence from computer and electronic product manufacturing, and healthcare. Appl Reg Growth Innov Models 64(1):83-106

\section{Submit your manuscript to a SpringerOpen ${ }^{\circ}$ journal and benefit from:}

- Convenient online submission

- Rigorous peer review

- Immediate publication on acceptance

- Open access: articles freely available online

- High visibility within the field

- Retaining the copyright to your article 